\title{
Habilidades e procedimentos de ensino de escrita para crianças com Transtorno do Espectro Autista: uma revisão
}

Writing skills and their teaching procedures for children with Autism Spectrum Disorder: a review

Habilidades de escritura y sus procedimientos de enseñanza para niños con Trastorno del Espectro Autista: una revisión

\section{Ana Carolina Sella}

Professora doutora na Universidade Federal de Alagoas, Maceió, Alagoas, Brasil.

carolsella@gmail.com

ORCID - https://orcid.org/0000-0002-9522-8379

Williany dos Santos Silva

Graduanda na Universidade Federal de Alagoas, Maceió, Alagoas, Brasil.

willianny.santos82@gmail.com

ORCID - https://orcid.org/0000-0002-9783-3935

Isvânia Alves dos Santos

Mestre pela Universidade Federal de Alagoas, Maceió, Alagoas, Brasil.

isvaniaa.santos@gmail.com

ORCID - https://orcid.org/0000-0002-8575-1377

Recebido em 11 de abril 2020

Aprovado em 10 de junho de 2020

Publicado em 8 de julho de 2020

\section{RESUMO}

A escrita é uma ferramenta fundamental para a humanidade: ela permite variadas formas de socialização, comunicação, organização, autoadvocacia e expressão artística. $O$ foco desta revisão sistemática da literatura foi organizar o conhecimento descrito em artigos de intervenção para o ensino de escrita para crianças com Transtorno do Espectro Autista (TEA). Buscou-se responder quais habilidades de escrita vêm sendo ensinadas para esta população e quais procedimentos vêm sendo utilizados para ensiná-las. Para tanto, foi realizada uma revisão bibliográfica em 5 fases interdependentes, que basearam uma análise sistemática. Após o término das 5 fases de análise, restaram 6 artigos com todos os critérios descritos. De forma geral, houve variabilidade na idade dos participantes, nos ambientes de intervenção, nas habilidades-alvo de escrita, nos procedimentos de ensino e no formato e mídia de implementação de tais procedimentos. Revisões bibliográficas periódicas são recomendadas e futuros estudos empíricos deveriam continuar a investigar as relações entre variáveis dependentes e independentes descritas nos estudos revisados e outras relações, além daquelas que foram alvos das intervenções encontradas também deveriam ser estudadas, buscando construir um corpo mais robusto de evidência para o ensino de diferentes habilidades de escrita para pessoas com TEA.

Palavras-chave: Ensino de escrita; autismo; revisão de literatura. 
http://dx.doi.org/10.5902/1984686X43482

\section{ABSTRACT}

Writing is a fundamental tool to humankind: it allows various forms of socialization, communication, organization, self-advocacy and artistic expression. The focus of this systematic literature review was to systematize the knowledge described in intervention articles aiming to teach writing to children with Autism Spectrum Disorder (ASD). This was an attempt to answer which writing skills are being taught to this population and which procedures are being used to teach them. A literature review was conducted in 5 interdependent phases that based a systematic analysis. After all 5 phases of analysis, 6 articles remained that had all of the described criteria. Overall, there was variability in the participants age, intervention settings, target writing skills, teaching procedures, and in procedure implementation format and media. Periodical literature reviews are recommended, and future empirical studies should continue to investigate the relations between the dependent and independent variables described in the revised studies and other relations, beyond the ones that were targeted at these interventions should be studied, aiming at building a more robust body of evidence for teaching different writing skills for people with ASD.

Keywords: Teaching of writing; autism; literature review.

\section{RESUMEN}

La escritura es una herramienta fundamental para la humanidad: permite diversas formas de socialización, comunicación, organización, autodefensa y expresión artística. El enfoque de esta revisión sistemática de literatura fue sistematizar el conocimiento descrito en los artículos de intervención para enseñar escritura a niños con TEA. Intentamos responder qué habilidades de escritura se han enseñado a esta población y qué procedimientos se han utilizado para enseñarles. Para este fin, se realizó una revisión bibliográfica en 5 fases interdependientes, que basaron un análisis sistemático. Después de las 5 etapas de análisis, quedan 6 artículos con todos los criterios descritos. En general, hubo una variabilidad en la edad de los participantes, en los ambientes de intervención, en las habilidades de escritura, en los procedimientos de enseñanza y en el formato y los medios para implementar dichos procedimientos. Se recomiendan revisiones bibliográficas periódicas y los futuros estudios empíricos deberían continuar investigando las relaciones entre las variables dependientes e independientes descritas en los estudios revisados y otras relaciones, además de los objetivos de las intervenciones encontradas, también deben estudiarse, buscando construir un cuerpo de evidencia más robusto para enseñar diferentes habilidades de escritura a personas con TEA.

Palabras clave: Enseñanza de escritura; autismo; revisión de literatura.

\section{Introdução}

Writing is one of the most important forms of human communication and one of the most difficult to do well. Writing provides a wonderfully flexible tool for acquiring, recalling, and disseminating knowledge with others while also offering an artistic medium for creative self-expression. (SADDLER; ELLISROBINSON; ASARO-SADDLER, 2018, p. 191) ${ }^{1}$.

A escrita é uma ferramenta fundamental para a humanidade: ela permite variadas formas de socialização, comunicação, organização, autoadvocacia e expressão artística. Por exemplo, na escola a escrita é usada para organizar atividades (agenda), trabalhos 
http://dx.doi.org/10.5902/1984686X43482

acadêmicos (outlines), ideias (redações) e demonstrar o conhecimento adquirido. Em contextos sociais, na era das mídias sociais, saber expressar e defender suas ideias de forma assertiva na escrita é importante em muitas situações. Usar aplicativos para a comunicação com a família e amigos garante a proximidade com pessoas fisicamente distantes. Além disso, em contextos profissionais, saber usar tais mídias, com escrita proficiente, é condição si ne qua non de muitos empregos. Muitas universidades, cursos de pós-graduação e empresas fazem a escolha dos melhores candidatos analisando sua proficiência na escrita (SADDLER et al., 2018; PENNINGTON, 2016; PENNINGTON, AULT, SCHUSTER; SANDERS, 2011). A escrita também proporciona manifestações artísticas magníficas, tanto que a tais manifestações é anualmente entregue o prêmio Nobel de Literatura.

Ao mesmo tempo em que possui importância fundamental para a sociedade, a escrita é uma das habilidades mais difíceis de serem adquiridas com fluência, ou seja, de acordo com a norma culta da língua e com rapidez e eficiência no escrever (SADDLER et al., 2018). Muitas razões podem ser responsáveis por essa dificuldade, como, por exemplo, a própria complexidade da escrita, a qual é composta por muitas subhabilidades e até mesmo o fato de as pessoas esquecerem que a escrita pode ser definida de diversas maneiras, a depender daquilo que se tem como objetivo final para cada aprendiz. Sem objetivos finais claros não é possível saber se a escrita foi ou não ensinada, pois não há parâmetros de análise (JOHNSON; STREET, 2013).

A definição de escrita aqui adotada parte de um referencial analíticocomportamental, o qual pressupõe que "a escrita" não existe enquanto habilidade única. $A$ escrita é uma rede de relações entre diversas habilidades, as quais variam das (a) mais simples e discretas (passíveis de serem observados o início e o fim de sua execução), como a escrita manuscrita ou digitação das letras e seus derivados (palavras, frases, parágrafos, textos, etc.) a partir de cópia e ditado até (b) as mais complexas, como a escrita de livros, que exigem não apenas os comportamentos motores da escrita manuscrita ou digitação, mas também o uso adequado da ortografia, gramática, pontuação e o próprio comportamento de edição do autor sobre o seu próprio texto. Sob esta perspectiva, as habilidades mais simples são vistas como independentes da leitura com compreensão, pois é possível copiar palavras sem haver leitura com compreensão. Conforme a escrita é definida como uma habilidade mais complexa, composta por outras 
http://dx.doi.org/10.5902/1984686X43482

habilidades, a intersecção entre leitura e escrita estreita-se, pois as habilidades de edição tornam-se parte imprescindível do processo.

Mais especificamente, possivelmente são necessários inúmeros pré-requisitos ou habilidades componentes para que a escrita fluente e complexa seja adquirida (JOHNSON; STREET, 2013), como, por exemplo, tempo de engajamento na tarefa, tempo de atenção seletiva e sustentada, habilidades de edição e de monitoramento da própria escrita, habilidades de organização, planejamento e revisão da escrita, autorregulação, uso correto de pontuação, ortografia e gramática, amplitude de vocabulário, coordenação motora para a escrita (em muitos casos, ainda cobrada), coesão no uso da linguagem, conhecimento de diferentes estruturas textuais e empatia em relação ao leitor (JOSEPH; KONRAD, 2009; PENNINGTON, 2016; SADDLER et al., 2018). Para cada um destes pré-requisitos, tanto de forma isolada quanto em conjunto, dificuldades podem surgir no processo de ensino e cada uma delas deve ser abordada de forma individual, baseando-se nos déficits e habilidades já adquiridas por cada aluno (JOHNSON; STREET, 2013).

Apesar de não haver muitos dados oficiais específicos acerca do desempenho em escrita enquanto habilidade medida separadamente (ou até mesmo em conjunto) da leitura no Brasil, os dados do SAEB (2017) mostram que apenas 1,6\% daqueles no Ensino Médio possui proficiência adequada em Língua Portuguesa, o que inclui habilidades de leitura e de escrita. O site Todos pela Educação já divulgou que "20\% dos jovens que concluem o ensino fundamental, e que moram nas grandes cidades, não dominam o uso da leitura e da escrita". De acordo com a Avaliação Nacional da Alfabetização de 2016, 33,95\% dos alunos não alcançaram níveis considerados suficientes em escrita (BRASIL, PNA, 2019). As estatísticas permitem a inferência que intervenções efetivas não vêm sendo implementadas em muitas situações de ensino, pois os resultados em avaliações nacionais não parecem demonstrar melhoras no desempenho dos alunos. Graham et al. (2001) e Santangelo e Olinghouse (2009) discutem que, para remediar este tipo de déficit, seriam necessárias intervenções efetivas, que levassem em consideração as dificuldades de cada aluno e que a eles provessem oportunidades estruturadas e frequentes de aprendizado. Além disso, para afirmar tal efetividade, seria necessário o monitoramento dos resultados de forma frequente. 
http://dx.doi.org/10.5902/1984686X43482

De acordo com Pennington e Delano (2012) e Pennington, Collins, Stenhoff, Turner e Gunselman (2014), crianças com TEA apresentam déficits na escrita que são ainda mais proeminentes do que aqueles de seus pares. Ao mesmo tempo, recebem menos oportunidades de aprender a escrever (JOSEPH; KONRAD, 2009; PENNINGTON; DELANO, 2012). Os próprios sintomas diagnósticos do TEA parecem estar correlacionados com os maiores déficits na escrita. Pennington e Delano (2012), por exemplo, discutem que a falta de habilidade de se colocar no lugar do outro e de ver o mundo sob esta outra perspectiva, os problemas de comportamento relacionados ao não seguimento de instruções e os déficits em linguagem podem intensificar em muito as dificuldades de aprendizado de escrita desta população.

Buscando formas de remediar tais déficits acentuados em crianças com TEA, alguns estudos realizaram revisões da literatura acerca do ensino de escrita para esta população e para pessoas com outras deficiências, comumente relacionadas ao TEA, como a intelectual. Apresentaremos todos os estudos de revisão encontrados em uma busca por tais estudos a seguir, descrevendo seus objetivos, métodos de revisão e resultados de forma geral (JOSEPH; KONRAD, 2009; PENNINGTON, 2016; PENNIGNTON; DELANO, 2012; SAMPAIO; OLIVEIRA, 2017). Aos leitores interessados em conhecer os critérios, métodos e resultados de tais revisões de forma mais detalhada, a leitura de tais estudos faz-se imprescindível.

Joseph e Konrad (2009) descreveram que seu objetivo era avaliar a efetividade de intervenções sobre o desempenho em escrita de crianças com deficiência intelectual (DI). Como este diagnóstico costuma ocorrer em diversos casos com TEA (Jensen; Smolen; Girirajan, 2020), considerou-se esta revisão relevante para o presente estudo. Joseph e Konrad basearam o seu estudo em três perguntas: (a) qual a quantidade e qualidade dos estudos que vêm sendo conduzidos; (b) o que tem se mostrado efetivo e, portanto, pode ser recomendado a profissionais da escola e da clínica; (c) quais insights e perguntas poderão ser abordados em pesquisas futuras sobre o ensino de escrita para pessoas com DI. Os estudos revisados foram publicados entre 1986 a 2007. Os resultados mostram que $29 \%$ dos participantes dos estudos também eram diagnosticados com TEA. A maior parte das pesquisas ocorreu em escolas e o principal delineamento experimental utilizado foi o de sujeito único. De forma geral, em relação às suas conclusões, os autores relataram que os estudos analisados não proviam dados suficientes para determinar quais 
http://dx.doi.org/10.5902/1984686X43482

dos métodos analisados (p. ex., instrução computadorizada para a escrita de frases) eram efetivos para esta população.

Pennington e Delano (2012), realizaram uma revisão da literatura com o objetivo de resumir e sistematizar as pesquisas empíricas acerca do ensino de escrita para alunos com TEA. Eles revisaram estudos entre 1994 e 2011, analisando quatro questões-alvo: quais habilidades têm sido alvo de intervenção, quais procedimentos têm sido utilizados e se estes são condizentes com as práticas baseadas em evidência ${ }^{2}$ para o ensino desta população, se as intervenções têm sido efetivas, e a qualidade das pesquisas de acordo com critérios como delineamento experimental, fidelidade de implementação, validade social e generalização das habilidades. De forma geral, os autores relatam que, apesar de todos os estudos terem descrito a aquisição ou o aumento na frequência de respostas corretas de escrita, apenas seis demonstraram relação funcional entre a intervenção e a variável dependente (habilidade de escrita). De acordo com os autores, nenhum dos estudos por eles analisados demonstrou o alcance dos critérios mínimos de aceitabilidade e significância para a magnitude dos efeitos da intervenção, tanto delineamentos de sujeito único como os de grupo. De acordo com a análise dos autores, alguns estudos relataram concordância entre observadores e fidelidade de implementação; outros testaram generalização e manutenção e poucos avaliaram validade social ou aceitação dos procedimentos. Estes resultados, quando olhados conjuntamente, levaram os autores a questionar a real efetividade dos procedimentos propostos nos estudos por eles analisados.

Pennington (2016) propôs-se a sintetizar pesquisas com foco no ensino de escrita para pessoas com deficiência severa, incluindo pessoas com TEA. A partir de sua síntese, o autor sugeriu um modelo de ensino de habilidades básicas de escrita de frases para esta população, visto que esta pode ser vista como base para a composição de outras formas textuais. De forma geral, o autor recomendou que sejam utilizadas as motivações (p. ex., preferências por personagens, alimentos, brinquedos) da criança no início do processo de escrita e que tecnologia assistiva seja usada quando dificuldades motoras estiverem associadas à deficiência ou transtorno. Além disso, ele recomendou o uso de tecnologias instrucionais que possuem evidência para o ensino desta populaçãoalvo (p. ex., o uso sistemas de dicas, reforçamento de comportamentos esperados, instrução sistemática e múltiplas oportunidades para o responder ativo do aluno) em 
http://dx.doi.org/10.5902/1984686X43482

conjunto com o monitoramento frequente dos resultados das intervenções para a aquisição destas habilidades.

Sampaio e Oliveira (2017) descreveram seu trabalho como um estudo bibliográfico para definir possíveis características comuns a crianças com TEA em relação aos processos de leitura e de escrita e identificar suas necessidades e potencialidades diante das especificidades desta população. As autoras não descrevem como chegaram aos estudos analisados em seu trabalho. Além disso, o fato de nenhum desses estudos ser específico à escrita, deve levar o leitor a ficar atento a generalizações que talvez não caibam no ensino dessa habilidade. As autoras discutiram a necessidade do estímulo constante para a obtenção de resultados satisfatórios com esse público, sem especificar mais objetivamente o significado de tal estimulação. Elas descreveram a necessidade de diferenciar o que é ser alfabetizado e letrado. Outras questões levantadas como parte do processo de escrita, mas que também não descrevem as habilidades de escrita em si, nem como estas seriam ensinadas, foram a decodificação dos signos presentes no dia a dia e a relação entre a cognição e a capacidade que cada pessoa tem para processar um conhecimento. As autoras discutiram também a necessidade de os professores lidarem de forma diferente com os diferentes perfis de crianças com TEA e a necessidade da criação de estratégias para potencializar as habilidades de seus alunos, mas sem prover exemplos concretos da efetivação de tais ideias. De forma geral, este estudo não descreveu de forma operacionalizada qual foi seu processo de análise da literatura e possibilidades de efetivação dos pontos levantados pelas autoras, mas foi o único estudo bibliográfico encontrado na língua portuguesa.

A partir destas revisões e de outros estudos da área, foi possível observar que não apenas novos estudos que avaliem intervenções precisam ser realizados, mas também revisões de literatura periódicas, como forma de atualizar pesquisadores e profissionais acerca das intervenções que vêm sendo estudadas. Dada a importância da escrita na vida em sociedade e os desafios adicionais que as pessoas com TEA podem enfrentar ao não adquirirem estas habilidades, o objetivo desta revisão foi sistematizar artigos de intervenção que tivessem como foco o ensino de escrita para crianças com TEA. A partir desta revisão, buscou-se prover, para uma audiência brasileira, conhecimento organizado sobre como a escrita tem sido ensinada para esta população. A pergunta-guia do trabalho foi: quais habilidades de escrita vêm sendo ensinadas à população com TEA e quais os procedimentos que vêm sendo utilizados para ensinar tais habilidades? No contexto do 
http://dx.doi.org/10.5902/1984686X43482

presente estudo, as habilidades de escrita não foram descritas a priori porque um dos objetivos era descrever o que a literatura vem classificando como tal.

\section{Método}

Esta revisão sistemática da literatura foi realizada em cinco fases, interdependentes entre si. As fases se encontram representadas na Figura 1.

Figura 1 - Esquematização das fases do processo de revisão

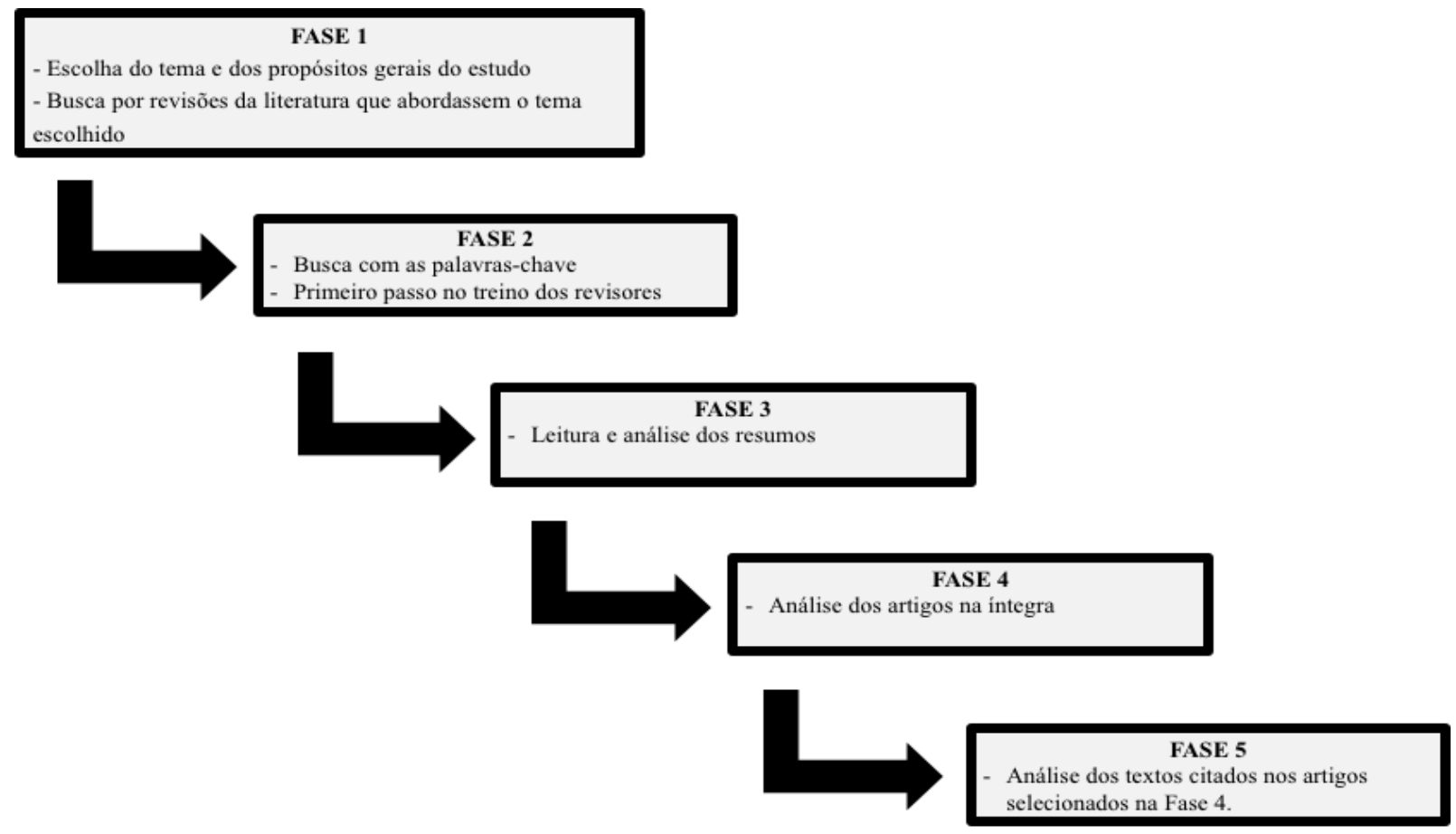

Fonte: Elaborada pelas autoras (2020).

Na Fase 1, seguindo-se os procedimentos propostos para revisões da literatura por The Writing Center, University of North Carolina at Chapel Hill (2018), estabeleceram-se o tema e os propósitos gerais desta revisão, seguidos de busca por revisões da literatura que abordassem este tema e pudessem guiar as perguntas de pesquisa a serem respondidas. Foram realizadas buscas por tais revisões da literatura nas bases Google Acadêmico, Proquest, Scielo e Lilacs, usando-se os termos ensino de escrita, crianças, Transtorno do Espectro Autista, revisão e seus correlatos em inglês (teachingwriting, children, Autism Spectrum Disorders, review), sem datas específicas. Os resultados desta busca encontram-se descritos na seção de Resultados e todos foram descritos na Introdução. A partir das revisões encontradas foram escolhidos (a) os descritores que seriam usados nas buscas em bases de dados e (b) a metodologia de análise a ser 
http://dx.doi.org/10.5902/1984686X43482

utilizada. Os primeiros descritores (primeira palavra a ser colocada no primeiro campo de busca) derivados das revisões foram as palavras autism, autismo spectrum disorder, developmental delay e seus correlatos em Português (autismo, Transtorno do Espectro Autista, atraso no desenvolvimento). As palavras writing, written expression, paragraph, sentence, writing skills, written communication e seus correlatos no Português (escrita, expressão escrita, parágrafo, frase, habilidades de escrita, comunicação escrita) foram escolhidas como descritores para o segundo campo de busca.

$\mathrm{Na}$ Fase 2, realizaram-se as buscas com os descritores descritos acima, nas bases de dados Proquest, Lilacs e Scielo. Seguindo os procedimentos descritos nas revisões da literatura encontradas na Fase 1, as buscas foram realizadas com o primeiro distrator entre aspas em um campo, seguido do segundo distrator entre aspas no segundo campo de busca. Todos os campos de busca foram limitados a títulos e resumos. Além disso, limitou-se a busca por artigos publicados nos anos de 2008 a 2018. O primeiro passo da Fase 2 foi o treino das revisoras, para garantir a concordância de observação entre as envolvidas no processo de busca e análise. O treino e as buscas prosseguiram até haver $100 \%$ de concordância entre as buscas das revisoras em cada uma das bases de dados (vide descrição detalhada nos resultados).

Na Fase 3, realizou-se a análise dos resumos dos artigos encontrados na Fase 2 e da página online do periódico na qual foi publicado. Esta Fase pode ser dividida em duas subfases. Primeiramente, o Quadro 1 foi construído e foram delineados os seguintes critérios de análise: (a) ano de publicação entre 2008 e 2018; (b) publicado em periódico científico revisado por pares (análise da página do periódico online); (c) artigo disponibilizado de forma gratuita e na íntegra online; (d) pelo menos um grupo de participantes do estudo ter diagnóstico de TEA e apenas de TEA; (e) idade das crianças (COLL; MARCHESI; PALACIOS, 2004) entre 0 a 11 anos de idade; (f) o estudo precisava ser empírico e de intervenção ${ }^{3}$, ou seja, os estudos tinham de incluir a manipulação de variável independente explícita com o intuito de gerar mudanças na variável dependente (estudos que apenas avaliaram comportamentos, sem intervir nos mesmos foram excluídos); (g) precisava haver observação e registro de comportamentos de escrita das crianças (variável dependente tinha de ser a escrita e não outro comportamento); (h) procedimentos de ensino foram citados no resumo. Para os artigos em que todas as respostas fossem sim, seriam registradas, adicionalmente, as habilidades de escrita citadas no resumo e os procedimentos de ensino. Artigos eram excluídos quando 
http://dx.doi.org/10.5902/1984686X43482

qualquer um dos itens tinha como resposta não. Artigos que se repetiam também foram excluídos, restando apenas uma instância dos mesmos na lista de análise.

Após o delineamento dos critérios de análise, foram realizadas cinco novas sessões de treino que seguiram a seguinte metodologia. Os 10 primeiros resumos resultantes da Fase 2 foram analisados pelas revisoras de forma independente. Em seguida, estas reuniram-se para calcular a concordância entre observadoras da análise, item por item do Quadro 1 para os 10 resumos-alvo. Se houvesse qualquer discordância, esta era discutida, as definições operacionais envolvidas no item em que houve discordância eram revistas e nova sessão de treino era realizada com os próximos 10 resumos. Na quinta sessão de treino, obteve-se $100 \%$ de concordância. A partir deste momento, uma das revisoras ficou responsável por analisar todos os resumos restantes e uma segunda observadora avaliou 20\% dos mesmos (amostra aleatória encontrada por sorteio a partir da numeração dos resumos), garantindo-se análise da concordância entre observadores em $20 \%$ dos resumos da Proquest e $20 \%$ da Scielo.

Quadro 1 - Quadro de Análise dos Resumos dos Artigos Selecionados (Fase 3)

\begin{tabular}{|l|l|l|}
\hline & $\begin{array}{c}\text { PRIMEIRO } \\
\text { OBSERVADOR }\end{array}$ & $\begin{array}{c}\text { SEGUNDO } \\
\text { OBSERVADOR }\end{array}$ \\
\hline Publicado entre 2008 e 2018? & & \\
\hline Publicado em periódico científico? & & \\
\hline Gratuito online na íntegra? & & \\
\hline Estudo empírico e de intervenção? & & \\
\hline $\begin{array}{l}\text { Um grupo de participantes com } \\
\text { apenas TEA? }\end{array}$ & & \\
\hline Idade de 0 a 11 anos? & & \\
\hline Observação e registro de escrita? & & \\
\hline Habilidades de escrita descritas? & & \\
\hline Procedimentos de ensino citados? & & \\
\hline
\end{tabular}

Fonte: Elaborado pelas autoras (2020).

$\mathrm{Na}$ Fase 4, as seções denominadas método ou metodologia e resultados de cada um dos artigos foram analisadas para responder a sete perguntas: (1) quais habilidades de escrita foram alvo da intervenção; (2) quais intervenções ou procedimentos foram utilizados para o ensino de escrita de pessoas com TEA; (3) qual o formato ou mídia utilizada para o ensino (p. ex., papel e lápis, eletro-eletrônicos; materiais tácteis); (4) quanto tempo de intervenção foi necessário para a criança aprender a habilidade-alvo; (5) quantos participantes e qual o diagnóstico, idade e sexo; (6) em que ambiente o estudo foi realizado (p. ex., casa, escola regular, escola especial, universidade); (7) quantos estudos 
possuíam respostas às perguntas 1 a 6 . O primeiro passo da Fase 4 foi a análise individual e independente de cada revisora do primeiro artigo disposto no Quadro 2. A seguir, as revisoras reuniram-se para verificar a concordância entre elas. Discordâncias foram discutidas até que se chegasse a um acordo quanto à análise. Este procedimento foi replicado para cada um dos seis artigos.

$\mathrm{Na}$ Fase 5, foram analisadas a introdução e as referências dos estudos selecionados na Fase 4 na busca por estudos adicionais para análise. Para realizar a Fase 5 foram seguidos os seguintes passos: (1) verificação na introdução de artigos citados sobre o ensino de escrita para pessoas com TEA; (2) verificação nas referências se as seguintes palavras estavam contidas no título das mesmas: autism ou Asperger; written ou writing, e teaching ou instruction ou seus sinônimos. Os correlatos em Português também foram buscados. Foram encontrados cinco novos estudos que foram analisados de acordo com os critérios descritos para as Fases 3 e 4.

\section{Resultados}

\section{Fase 1}

Nesta fase, foram encontradas quatro revisões da literatura (JOSEPH; KONRAD, 2009; PENNINGTON; DELANO, 2012; PENNINGTON, 2016; SAMPAIO; OLIVEIRA, 2017). Estas revisões foram lidas e as perguntas de pesquisa e variáveis de análise por elas propostas foram analisadas. Nossas perguntas de pesquisa, os descritores utilizados, os pontos a serem analisados em cada estudo e a descrição da metodologia tiveram por base estas quatro revisões. Além disso, estas quatro revisões estão descritas na introdução e buscam mostrar ao leitor esforços similares ao do presente trabalho.

\section{Fase 2}

$\mathrm{Na}$ primeira busca realizada nas bases de dado alvo, ao utilizarem os mesmos descritores, entre aspas, na ordem de campos de busca estabelecida, com os mesmos limites escolhidos foram gerados resultados bastante discrepantes entre as revisoras. Os resultados obtidos por cada revisora foram impressos e identificadas semelhanças e diferenças entre o que foi obtido por cada uma. No final de tal análise, foi calculado o índice de concordância em relação aos resultados obtidos em cada base de dados, dividindo-se o número de estudos que todas encontraram pelo maior número total de estudos encontrados e multiplicado por 100. As buscas na base Lilacs derivaram em 348 
resultados e obteve-se $11 \%$ de concordância entre as revisoras. A busca na base Proquest resultou em $56 \%$ de concordância dentre 381 resultados encotrados. Houve $78 \%$ de concordância nos 12 resultados encontrados na base Scielo. Provavelmente as diferenças deram-se porque as buscas foram efetuadas em computadores, servidores e navegadores diferentes. Dada a concordância muito pequena com a base Lilacs, ela foi excluída. Para as outras duas bases, a busca repetiu-se para cada revisora, de forma independente, mas utilizando-se um único computador, com o mesmo navegador e houve concordância entre observadores, encontrando-se os mesmos 393 estudos ao todo (Proquest e Scielo juntas). Estes estudos foram analisados na Fase 3.

\section{Fase 3}

Dentre os 393 resultados encontrados na Fase 2, muitos artigos repetiam-se. Estes artigos tiveram suas duplicações eliminadas, restando apenas 57 artigos para a análise sob a ótica das perguntas do Quadro 1. Esta análise de resumos derivou em apenas 6 estudos restantes: Asaro-Saddler e Saddler (2010); Bishop et al. (2015), Carlson et al. (2009), Pennington et al. (2011); Pennington et al. (2014) e Pennington et al. (2012). Estes seis artigos foram publicados dentro do período definido (2008 a 2018), nos periódicos Education and Training in Autism and Developmental Disabilities (2 artigos), Assistive Technology Outcomes \& Benefits, Exceptional Children, Electronic Journal of Research in Educational Psychology, Education and Treatment of Children com um artigo em cada periódico, ou seja, tais artigos encontram-se dispersos. Importante ressaltar que todos estes artigos estão disponíveis online, de forma gratuita e na íntegra, mesmo que a permissão de acesso seja apenas para a leitura. Os seis artigos eram empíricos e de intervenção. Somando-se os participantes desses estudos, havia 17 crianças com TEA, com idades entre 4 e 14 anos. Os seis artigos citaram em seus resumos as habilidadesalvo de escrita e os procedimentos de ensino utilizados.

\section{Fase 4}

Nesta fase, foi realizada a leitura do método e dos resultados dos artigos. O artigo de Bishop, Sawyer, Alber-Morgan e Boggs (2015) foi excluído, dado que sua leitura revelou que a idade da população-alvo do estudo era maior do que aquela que o resumo levava a crer. O título do estudo de Bishop et al. (2015) mencionava middleschoolers e o resumo não era específico, portanto, poderia incluir crianças de 11 anos de idade. 
http://dx.doi.org/10.5902/1984686X43482

Todavia, no corpo do texto, eles descreveram que as crianças tinham entre 12 e 14 anos de idade. Portanto, este estudo foi excluído da análise, restando 5 artigos para a análise.

Com a exclusão do artigo de Bishop et al. (2015), o número de participantes com TEA foi reduzido para 14 crianças com idade entre 4 e 10 anos, sendo 13 do sexo masculino (12 diagnosticadas com autismo e um com Síndrome de Asperger) e apenas uma do sexo feminino (diagnosticada com atraso no desenvolvimento).

As habilidades-alvo de intervenção encontradas variaram de simples (escrita de letras isoladas) até complexas (p. ex., comportamento de escrita de histórias). Especificamente, as variáveis dependentes dos estudos foram: (a) número de frases completas e/ou palavras utilizadas para a construção de histórias; (b) coesão entre as frases escritas; (c) número de elementos de história (p. ex. identificação de personagens, cenário, descrição do tempo, local onde ocorreu a história; desfecho do enredo); (d) manutenção da escrita baseada em computador; (e) generalização para novos templates ou topografias de respostas escritas ou vocais; (f) escrita manuscrita sem dicas; (g) qualidade geral da escrita da história (p. ex. ideias, organização, estrutura de sentenças, da gramática e do vocabulário); (h) evidência de planejamento; e (i) legibilidade das letras. Para o estudo em que se analisou a escrita isolada das letras, as variáveis foram: (i; j) tamanho e legibilidade das letras; (k) letras que permaneceram dentro do modelo delineado ( $80 \%$ de precisão).

Os principais procedimentos utilizados no ensino dessas habilidades encontram-se resumidos a seguir. O primeiro procedimento era constituído por uma série de componentes: prompt atencional + prompt simultâneo para a escrita da primeira frase da história + elogios para frase correta + prompts para as próximas frases + feedback auditivo ao término da tarefa de construção de história. Neste procedimento, o professor escolhia uma das telas que seria usada para a escrita computadorizada de uma históriaalvo pelo aluno. Assim que a tela abria, o professor apresentava o prompt atencional "olhe". Assim que o aprendiz olhasse para a tela, o professor dizia: "escreva uma história" e imediatamente apresentava o prompt gestual de apontar para cada uma das células presentes na tela, sendo estas compostas por uma palavra ou figura. Para cada uma das frases que comporia a história, o professor apresentava este prompt de apontar sobre cada célula. A construção de cada frase de forma correta resultava em elogios. Após a construção de todas as frases (ou seja, da história completa), o professor clicava em um botão que contava a história completa (feedback auditivo) ${ }^{4}$. 0 segundo procedimento 
http://dx.doi.org/10.5902/1984686X43482

descrito foi o desenvolvimento de estratégia de autorregulação e de planejamento (SRSD). O SRSD, do inglês self-regulated strategy development, refere-se à uma abordagem instrucional, na qual são ensinadas aos alunos estratégias para que eles mesmos possam monitorar, avaliar e revisar o seu processo de escrita. De acordo com Graham e Harris (2005), há cinco grandes componentes para o SRSD: discutir com o aluno quando e como usar a estratégia, modelar o uso da estratégia, criar mnemônicos para que o aluno possa lembrar o que deve ser feito, oferecer suporte na forma de dicas e feedbacks e encorajar o uso independente das estratégias em diversos contextos. No contexto dos estudos encontrados na presente revisão, o SRSD incluía principalmente a utilização de mnemônicos (chamados POW e WWW); o uso da escrita colaborativa em que cada participante criava uma história com o suporte do instrutor; e um organizador gráfico, o qual era retirado em fases posteriores até que a escrita de uma história ocorresse sem suporte ou assistência. O terceiro procedimento foi parte do Handwriting without tears $\AA$, o qual é um pacote de intervenção da empresa Learning without tears. Tal intervenção faz uso da estimulação visual, tátil, auditiva e cinestésica para ensinar a formação, espaçamento e sequenciamento de letras. Antes de iniciar o programa 0 professor pode utilizar as avaliações disponibilizadas pela empresa: de prontidão para a escrita, de avaliação de escrita em letra bastão e de escrita em letra cursiva para iniciar com as lições de acordo com o nível do aluno. No estudo de Carlson et al. (2009), as letras-alvos $(T, H, D$ e $F)$ foram ensinadas no formato bastão, com o uso de modelação e instruções acerca dos passos sequenciais que resultariam na escrita da letra, além dos materiais previstos no programa.

O formato e as mídias ${ }^{5}$ utilizadas no ensino das habilidades-alvo foram variados, incluindo desde computadores e softwares específicos até materiais simples, como lápis e papel. Em geral, utilizou-se: Instrução Assistida por Computador (CAI) ${ }^{6}$ apresentadas pelo software Pixwriter ${ }^{\mathrm{TM}}$, computador pessoal IBM, equipado com tela sensível ao toque e uso do software Clicker 5TM (alternativa ao Pixwriter ${ }^{\mathrm{TM}}$ ), cartões com histórias escritas, papel, lápis, imagens em preto e branco, lista de instruções e lembretes, mnemônicos POW e WWW, programa Handwriting Without Tears $\AA$, um quadro de $3 \times 5$, giz, uma pequena esponja, um copo água, um pedaço de papel toalha, planilhas para cada uma das letras e marcadores de texto para usar nessa planilha.

Os ambientes variaram entre sala de educação especial, sala de aula independente para crianças com TEA (self-contained classroom for children with $A S D$ ), qualquer espaço 
desocupado na escola, sendo alterado a depender da disponibilidade das salas durante os dias de intervenção.

Em relação ao tempo necessário para aprendizagem dos comportamentos-alvo, o menor número de sessões foi observado em Asaro-Sanddler e Sanddler (2010), com 6 sessões e o maior número foi relatado em Pennington et al. (2011), com um total de 56 sessões para um dos participantes alcançar o critério de desempenho. Vale ressaltar que a imprecisão do gráfico de Pennington et al. (2012) não permitiu mensurar o número exato de sessões até o alcance do critério de aprendizagem do estudo. No entanto, na descrição dos resultados, os autores esclarecem que foi preciso uma média de 11 sessões de treinamento para o desenvolvimento de cada conjunto de histórias referente aos personagens trabalhados (no estudo, os personagens Monke, Barney e Spongebob).

\section{Fase 5}

$\mathrm{Na}$ Fase 5, foram analisados novos estudos, presentes na introdução e referências dos estudos aprovados na Fase 4. O Quadro 3 apresenta os estudos que possuíam todos os critérios de análise, das Fases 3, 4 e 5.

Quadro 3 - Artigos com todos os critérios de análise das Fases 3, 4 e 5

\begin{tabular}{|c|c|c|c|c|c|c|}
\hline $\begin{array}{c}\text { Autor(es) e } \\
\text { ano }\end{array}$ & $\begin{array}{l}\text { Habilidades } \\
\text { alvo }\end{array}$ & $\begin{array}{l}\text { Intervenções de } \\
\text { ensino } \\
\text { (procedimentos) }\end{array}$ & $\begin{array}{l}\text { Formato ou } \\
\text { mídia }\end{array}$ & $\begin{array}{c}\text { Sessões para } \\
\text { a } \\
\text { aprendizagem }\end{array}$ & $\begin{array}{l}\text { Número de } \\
\text { participante, } \\
\text { idade, sexo e } \\
\text { diagnóstico }\end{array}$ & Ambiente \\
\hline $\begin{array}{l}\text { ASARO \& } \\
\text { SADDLER } \\
(2009)^{\star}\end{array}$ & $\begin{array}{l}\text { Construção de } \\
\text { história escrita } \\
\text { (número de } \\
\text { elementos e } \\
\text { qualidade } \\
\text { holística) }\end{array}$ & $\begin{array}{l}\text { Desenvolvimento } \\
\text { de estratégia de } \\
\text { auto regulação e } \\
\text { de planejamento } \\
\text { (SRSD); } \\
\text { Estratégia de } \\
\text { planejamento e } \\
\text { redação da } \\
\text { história } \\
\text { (mnemônico } \\
\text { POW e WWW) }\end{array}$ & $\begin{array}{l}\text { Imagens: } \\
\text { desenhadas } \\
\text { em preto e } \\
\text { branco } \\
\text { Mnemônico: } \\
\text { POW, WWW } \\
\text { Gráfico de } \\
\text { foguetes } \\
\text { Declaração } \\
\text { pessoal } \\
\text { Papel e lápis }\end{array}$ & 7 lições & $\begin{array}{l}1 \text { menino } \\
\text { John: } 10 \text { anos } \\
\text { Síndrome de } \\
\text { Asperger }\end{array}$ & $\begin{array}{l}\text { Biblioteca } \\
\text { ou sala de } \\
\text { multiuso }\end{array}$ \\
\hline
\end{tabular}


http://dx.doi.org/10.5902/1984686X43482

Quadro 3 - Artigos com todos os critérios de análise das Fases 3, 4 e 5

\begin{tabular}{|c|c|c|c|c|c|c|}
\hline $\begin{array}{c}\text { Autor(es) e } \\
\text { ano }\end{array}$ & $\begin{array}{l}\text { Habilidades } \\
\text { alvo }\end{array}$ & $\begin{array}{l}\text { Intervenções } \\
\text { de ensino } \\
\text { (procedimento } \\
\text { s) }\end{array}$ & $\begin{array}{l}\text { Formato ou } \\
\text { mídia }\end{array}$ & $\begin{array}{c}\text { Sessões para } \\
a \\
\text { aprendizagem }\end{array}$ & $\begin{array}{c}\text { Número de } \\
\text { participante, } \\
\text { idade, sexo e } \\
\text { diagnóstico }\end{array}$ & Ambiente \\
\hline $\begin{array}{l}\text { ASARO- } \\
\text { SADDLER } \\
\text { SADDLER } \\
(2010)\end{array}$ & $\begin{array}{l}\text { Construção de } \\
\text { história escrita } \\
\text { (número de } \\
\text { elementos; } \\
\text { qualidade } \\
\text { holística; } \\
\text { número total de } \\
\text { palavras e } \\
\text { tempo de } \\
\text { planejamento) }\end{array}$ & $\begin{array}{l}\text { Desenvolviment } \\
\text { o de estratégia } \\
\text { de auto } \\
\text { regulação e de } \\
\text { planejamento } \\
\text { (SRSD); } \\
\text { Estratégia de } \\
\text { planejamento e } \\
\text { redação da } \\
\text { história } \\
\text { (mnemônico } \\
\text { POW e WWW) }\end{array}$ & $\begin{array}{l}\text { Imagens: } \\
\text { desenhadas } \\
\text { em preto e } \\
\text { branco } \\
\text { Mnemônico: } \\
\text { POW, WWW } \\
\text { Gráfico de } \\
\text { foguetes } \\
\text { Declaração } \\
\text { pessoal } \\
\text { Papel e lápis }\end{array}$ & 6 lições & $\begin{array}{l}3 \text { meninos } \\
\text { Mike: } 9 \text { anos; } \\
\text { Síndrome de } \\
\text { Asperger } \\
\text { Justin: } 6 \\
\text { anos; autismo } \\
\text { George: } 7 \\
\text { anos; autismo }\end{array}$ & $\begin{array}{l}\text { Qualquer } \\
\text { espaço } \\
\text { disponível } \\
\text { (ex. outra } \\
\text { sala de } \\
\text { aula, sala } \\
\text { de } \\
\text { orquestra, } \\
\text { ou sala de } \\
\text { conferência } \\
\text { s) }\end{array}$ \\
\hline $\begin{array}{l}\text { CARLSON, } \\
\text { MCLAUGHLI } \\
\text {; DERBY; } \\
\text { BLECHER } \\
\text { (2009) }\end{array}$ & $\begin{array}{l}\text { Tamanho da } \\
\text { letra (cobrir pelo } \\
\text { menos } 80 \% \text { da } \\
\text { caixa) } \\
\text { Legibilidade das } \\
\text { letras } \mathrm{T}, \mathrm{H}, \mathrm{D} \text { e } \\
\mathrm{F} \text { (pontua se for } \\
\text { maiúscula) } \\
\text { Cartas dentro do } \\
\text { modelo } \\
\text { delineado ( } 80 \% \\
\text { de precisão) }\end{array}$ & $\begin{array}{l}\text { Repetição de } \\
\text { letra com } \\
\text { esponja } \\
\text { molhada na } \\
\text { lousa. } \\
\text { Planilhas do } \\
\text { Handwriting } \\
\text { Without Tears® } \\
\\
\text { Escrita de carta } \\
\text { a partir do } \\
\text { modelo e de } \\
\text { instrução. }\end{array}$ & $\begin{array}{l}\text { - Programa } \\
\text { Handwriting } \\
\text { Without } \\
\text { Tears®: } \\
\text { Quadro } \\
\text { negro } \\
\text { Giz } \\
\text { Esponja } \\
\text { pequena } \\
\text { Copo de } \\
\text { água e papel } \\
\text { toalha } \\
\text { Planilhas } \\
\text { para letras } \\
\text { (T, H, D, F) } \\
\text { Marca-texto }\end{array}$ & $\begin{array}{l}\text { Participante 1: } \\
\text { 26 (T 11+H } \\
\text { 8+D5+F 2) } \\
\text { Participante 2: } \\
12 \text { (T 7+ H4+ } \\
\text { D1+ F 0) }\end{array}$ & $\begin{array}{l}2 \text { (1 menino e } \\
1 \text { menina) } \\
\text { Participante 1: } \\
4 \text { anos e 9 } \\
\text { meses; } \\
\text { autismo } \\
\text { Participante 2: } \\
4 \text { anos e } 3 \\
\text { meses; atraso } \\
\text { no } \\
\text { desenvolvime } \\
\text { nto }\end{array}$ & $\begin{array}{l}\text { Sala de } \\
\text { aula pré- } \\
\text { escolar de } \\
\text { educação } \\
\text { especial } \\
\text { independen } \\
\text { te }\end{array}$ \\
\hline $\begin{array}{l}\text { PENNINGT } \\
\text { ON; AULT; } \\
\text { SCHUSTER; } \\
\text { SANDERS } \\
(2011)\end{array}$ & $\begin{array}{l}\text { Construção de } \\
\text { frase inicial da } \\
\text { história dentro } \\
\text { de } 5 \mathrm{~s} \\
\text { Construção de } \\
\text { frases } \\
\text { completas } \\
\text { Número de } \\
\text { palavras e } \\
\text { frases usadas } \\
\text { Coesão entre as } \\
\text { frases escritas } \\
\text { Novas } \\
\text { topografias de } \\
\text { escrita } \\
\text { (caligrafia) }\end{array}$ & $\begin{array}{l}\text { Prompt } \\
\text { simultâneo } \\
\text { (sugestão de } \\
\text { atenção + } \\
\text { escrita da } \\
\text { história } \\
\text { apontando para } \\
\text { cédula) + } \\
\text { elogios } \\
\text { verbais+ pedido } \\
\text { de seleção de } \\
\text { palavras até o } \\
\text { término da } \\
\text { história+ } \\
\text { feedback } \\
\text { auditivo (leitura } \\
\text { da história) }\end{array}$ & $\begin{array}{l}\text { Instrução } \\
\text { Assistida por } \\
\text { Computador } \\
\text { (CAI) com o } \\
\text { software } \\
\text { PixwriterT } \\
\text { Computador } \\
\text { pessoal IBM, } \\
\text { equipado } \\
\text { com tela } \\
\text { sensível ao } \\
\text { toque } \\
\text { Software } \\
\text { Clicker 5TM }\end{array}$ & $\begin{array}{l}\text { Paul: } 09 \\
\text { Caleb: } 09 \\
\text { Jason: Não } \\
\text { atingiu critérios } \\
\text { de } \\
\text { aprendizagem. }\end{array}$ & $\begin{array}{l}3 \text { meninos } \\
\text { Paul: } 7 \text { anos; } \\
\text { autismo } \\
\text { Caleb: } 10 \\
\text { anos; autismo } \\
\text { Jason: } 8 \\
\text { anos; autismo }\end{array}$ & $\begin{array}{l}\text { Sala de } \\
\text { aula } \\
\text { independen } \\
\text { te para } \\
\text { crianças } \\
\text { com TEA }\end{array}$ \\
\hline
\end{tabular}


http://dx.doi.org/10.5902/1984686X43482

Quadro 3 - Artigos com todos os critérios de análise das Fases 3, 4 e 5

\begin{tabular}{|c|c|c|c|c|c|c|}
\hline \multicolumn{7}{|r|}{ (conclusao) } \\
\hline $\begin{array}{c}\text { Autor(es) e } \\
\text { ano }\end{array}$ & $\begin{array}{c}\text { Habilidades } \\
\text { alvo }\end{array}$ & $\begin{array}{l}\text { Intervenções } \\
\text { de ensino } \\
\text { (procedimento } \\
\text { s) }\end{array}$ & $\begin{array}{l}\text { Formato ou } \\
\text { mídia }\end{array}$ & $\begin{array}{c}\text { Sessões para } \\
\text { a } \\
\text { aprendizagem }\end{array}$ & $\begin{array}{c}\text { Número de } \\
\text { participante, } \\
\text { idade, sexo e } \\
\text { diagnóstico }\end{array}$ & Ambiente \\
\hline $\begin{array}{l}\text { PENNINGTO } \\
\text { N; AULT; } \\
\text { SCHUSTER; } \\
\text { SANDERS } \\
(2011)\end{array}$ & $\begin{array}{l}\text { Construção de } \\
\text { frase inicial da } \\
\text { história dentro } \\
\text { de } 5 \text { s } \\
\text { Construção de } \\
\text { frases completas } \\
\text { Número de } \\
\text { palavras e frases } \\
\text { usadas } \\
\text { Coesão entre as } \\
\text { frases escritas } \\
\text { Novas } \\
\text { topografias de } \\
\text { escrita } \\
\text { (caligrafia) }\end{array}$ & $\begin{array}{l}\text { Prompt } \\
\text { simultâneo } \\
\text { (sugestão de } \\
\text { atenção + } \\
\text { escrita da } \\
\text { história } \\
\text { apontando para } \\
\text { cédula) + } \\
\text { elogios verbais+ } \\
\text { pedido de } \\
\text { seleção de } \\
\text { palavras até o } \\
\text { término da } \\
\text { história+ } \\
\text { feedback } \\
\text { auditivo (leitura } \\
\text { da história) }\end{array}$ & $\begin{array}{l}\text { Instrução } \\
\text { Assistida por } \\
\text { Computador } \\
\text { (CAI) com o } \\
\text { software } \\
\text { Pixwriter }^{\mathrm{TM}} \\
\text { Computador } \\
\text { pessoal IBM, } \\
\text { equipado } \\
\text { com tela } \\
\text { sensível ao } \\
\text { toque } \\
\text { Software } \\
\text { Clicker 5TM }\end{array}$ & $\begin{array}{l}\text { Paul: } 09 \\
\text { Caleb: } 09 \\
\text { Jason: Não } \\
\text { atingiu critérios } \\
\text { de } \\
\text { aprendizagem. }\end{array}$ & $\begin{array}{l}3 \text { meninos } \\
\text { Paul: } 7 \text { anos; } \\
\text { autismo } \\
\text { Caleb: } 10 \\
\text { anos; autismo } \\
\text { Jason: } 8 \text { anos; } \\
\text { autismo }\end{array}$ & $\begin{array}{l}\text { Sala de } \\
\text { aula } \\
\text { independen } \\
\text { te para } \\
\text { crianças } \\
\text { com TEA }\end{array}$ \\
\hline $\begin{array}{l}\text { PENNINGTO } \\
\text { N; COLLINS; } \\
\text { STENHOFF; } \\
\text { TURNER; } \\
\text { GUNSELMA } \\
\text { N (2014) }\end{array}$ & $\begin{array}{l}\text { Número de } \\
\text { frases na história } \\
\text { Coesão entre as } \\
\text { frases escritas } \\
\text { Número de } \\
\text { elementos de } \\
\text { história } \\
\text { Manutenção da } \\
\text { escrita baseada } \\
\text { em computador } \\
\text { Generalização } \\
\text { para novos } \\
\text { template } \\
\text { Escrita } \\
\text { manuscrita sem } \\
\text { dicas }\end{array}$ & $\begin{array}{l}\text { Prompt } \\
\text { simultâneo } \\
\text { (sugestão de } \\
\text { atenção + } \\
\text { apontar + } \\
\text { elogios gerais } \\
\text { pelo } \\
\text { comportamento } \\
\text { na tarefa)+ } \\
\text { elogios à } \\
\text { história + } \\
\text { feedback } \\
\text { auditivo do } \\
\text { software (leitura } \\
\text { da história) }\end{array}$ & 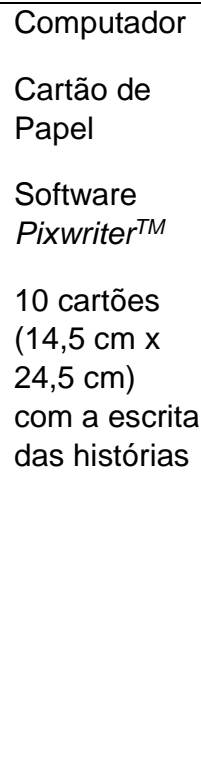 & $\begin{array}{l}\text { Ryan: } 17 \\
\text { Myron: } 28 \\
\text { Joe: } 36 \\
\text { Marc: } 48 \\
\text { Duncan: } 56\end{array}$ & $\begin{array}{l}5 \text { meninos } \\
\text { Ryan: } 7 \text { anos; } \\
\text { autismo } \\
\text { Myron: } 7 \\
\text { anos; autismo } \\
\text { Joe: } 10 \text { anos; } \\
\text { autismo } \\
\text { Marc: } 9 \text { anos; } \\
\text { autismo } \\
\text { Duncan: } 7 \\
\text { anos; autismo }\end{array}$ & $\begin{array}{l}\text { Sala de } \\
\text { educação } \\
\text { especial } \\
\text { auto- } \\
\text { contida ou } \\
\text { cômodo } \\
\text { usado para } \\
\text { fonoterapia }\end{array}$ \\
\hline $\begin{array}{l}\text { PENNINGTO } \\
\text { N; } \\
\text { STENHOFF; } \\
\text { GIBSON; } \\
\text { BALLOU } \\
(2012)\end{array}$ & $\begin{array}{l}\text { Número de } \\
\text { frases completas } \\
\text { na história } \\
\text { Construção de } \\
\text { história coesa } \\
\text { com } 3 \text { frases } \\
\text { Generalização } \\
\text { para novas } \\
\text { topografias de } \\
\text { escrita } \\
\text { (caligrafia). }\end{array}$ & $\begin{array}{l}\text { Prompt } \\
\text { simultâneo } \\
\text { (sugestão de } \\
\text { atenção + } \\
\text { comando vocal } \\
\text { + prompt } \\
\text { gestual) + } \\
\text { elogios verbais } \\
\text { + feedback } \\
\text { auditivo do } \\
\text { software (leitura } \\
\text { da história) }\end{array}$ & $\begin{array}{l}\text { Instrução } \\
\text { Assistida por } \\
\text { Computador } \\
\text { (CAI) com o } \\
\text { software } \\
\text { Pixwriter }^{\mathrm{TM}} \\
\text { Impressora } \\
\text { jato de tinta } \\
\text { colorida } \\
\text { Papel e lápis }\end{array}$ & $\begin{array}{l}\text { Jaden: cerca } \\
\text { de } 35\end{array}$ & $\begin{array}{l}1 \text { menino } \\
\text { Jaden: } 7 \text { anos; } \\
\text { autismo }\end{array}$ & $\begin{array}{l}\text { Sala de } \\
\text { recursos de } \\
\text { educação } \\
\text { especial }\end{array}$ \\
\hline
\end{tabular}

Fonte: Elaborado pelas autoras (2020). * Artigo advindo da nova análise, realizada na Fase 5. 
A pesquisa de Asaro e Saddler (2009), nova inserção a partir da análise da introdução e referências, contou com um único participante do sexo masculino, de 10 anos de idade e com o diagnóstico de autismo. A habilidade-alvo de escrita analisada foi a de construção de história, observando-se o número de elementos básicos das histórias e qualidade holística da história (Escala de 8 pontos do trabalho de Graham e Harris (1989). O estudo utilizou o desenvolvimento de estratégia de autorregulação e de planejamento (SRSD), sendo seus elementos similares a de outros estudos encontrados. As mídias utilizadas foram imagens desenhadas em preto e branco; os dispositivos mnemônicos POW e WWW; um organizador gráfico (gráfico de foguetes) e uma declaração pessoal. Ainda que não esteja explicitado, provavelmente tenham feito uso de papel e lápis também. Os autores não mencionaram a quantidade de sessões necessária para o desenvolvimento das habilidades-alvo, no entanto, esclarecem que foram desenvolvidas e aplicadas 7 lições, sendo que o pesquisador se reuniu com o participante por 30 minutos, três vezes na semana durante 5 semanas. $O$ participante passou a escrever histórias completas (em termos de elementos da história) e com maior qualidade.

\section{Discussão e Conclusões}

O objetivo deste trabalho foi sistematizar o conhecimento disposto em artigos de intervenção para o ensino de escrita para crianças com TEA. Buscou-se responder quais habilidades de escrita vêm sendo ensinadas à população com TEA e quais os procedimentos que vêm sendo utilizados para ensiná-las. De forma geral, o presente estudo contribui com a literatura ao sistematizar informações acerca de diversas variáveis de análise em relação a intervenções para o ensino de escrita para pessoas com TEA.

No trabalho realizado, foram analisados estudos de intervenção publicados entre os anos de 2008 e 2018. Nenhum desses artigos foi publicado em periódicos brasileiros. Este dado demonstra a necessidade de condução de pesquisas empíricas e sistemáticas para a produção de evidência para o ensino de escrita para pessoas com TEA no Brasil. Tais evidências auxiliariam profissionais no processo de tomada de decisão acerca de intervenções educacionais para esta população (KRATOCHWILL; STOIBER, 2002; SANTOS; SELLA; RIBEIRO, 2019) e ofereceriam mais informações para pesquisadores interessados no tema. 
http://dx.doi.org/10.5902/1984686X43482

Os seis artigos selecionados foram publicados em seis periódicos diferentes. Como discutido por Sella, Chiodelli e Mendes (2013), tal dissipação de publicações, sem a presença de revisões da literatura para sistematizar tal conhecimento, especialmente na literatura nacional, pode dificultar o acesso a estas informações. Revisões de literatura periódicas e buscas em bases de dados (ao invés de em periódicos específicos) serão provavelmente necessárias para auxiliar o pesquisador ou o profissional na busca por conhecimento nesta área. Esperamos que o presente trabalho possa oferecer algum direcionamento em tais buscas.

Em relação a comportamentos-alvo, de forma geral, foram encontrados 11 alvos, os quais variaram entre bastante complexos (qualidade geral na escrita de história) a simples (tamanho e legibilidade de letras). Tal variabilidade reflete os inúmeros componentes que, juntos, resultam em produtos que são chamados de escrita. Apesar de tal variabilidade poder representar um problema por não ser possível tratar em profundidade de um comportamento-alvo específico, e, portanto, não permitir a pesquisadores e profissionais a tomada de decisões mais precisas acerca das estratégias de ensino a serem adotadas, tal variabilidade também pode ser importante por demonstrar alternativas para diferentes comportamentos-alvos de escrita que possam estar sendo ensinados a diferentes populações com TEA. Se pensarmos que alguns autores chegam a descrever 13 habilidades envolvidas na escrita (JOHNSON; STREET, 2013) a descrição de tal variabilidade é importante por atentar o leitor para a necessidade de especificação de qual habilidade de escrita ele está buscando, observando ou com a qual realizará sua intervenção.

Uma observação referente aos estudos e as habilidades ensinadas nos mesmos fazse pertinente. Com exceção do estudo de Carlson et al. (2009), os outros estudos exigiam dos participantes com TEA pré-requisitos complexos (p. ex., acuidade visual e auditiva, respostas vocais ecóicas, habilidades de uso do mouse de computador, vocabulário de leitura de palavras impressas, habilidades de cópia manuscrita, capacidade de permanecer sentado no local de realização do ensino por 10 minutos, localizar e selecionar um link usando o mouse, seguir instruções verbais de um passo e responder após dicas gestuais). Para aqueles iniciando o ensino da escrita, garantir a aprendizagem dos pré-requisitos sempre será necessário antes que tarefas mais complexas sejam apresentadas. Apenas para a exemplificação, Johnson e Street (2013) descrevem que saber copiar letras ou palavras, com escrita manuscrita ou digitada, e escrever a partir de 
http://dx.doi.org/10.5902/1984686X43482

ditado (letra manuscrita ou digitada) são as habilidades mais básicas que precisam ser estabelecidas antes que componentes intermediários (ou seja, mais complexos) da escrita possam ser ensinados (p. ex., pontuação, ortografia e gramática). As últimas habilidades a serem ensinadas seriam aquelas que dependem de todas as anteriores e incluem a necessidade de edição da própria escrita (p. ex., a escrita de narrativas e dissertações).

A busca foi realizada em artigos cujos participantes tinham entre 0 e 10 anos de idade, com diagnóstico de TEA. Dentre os participantes, seis tinham 7 anos de idade e os outros, entre 4 e 10 anos e a maior parte dos diagnósticos foi descrita como autismo (12 crianças). Os resultados aqui descritos, portanto, referem-se mais aos anos iniciais do Ensino Fundamental, para esta população específica e terão maior utilidade para profissionais que trabalhem com esta população.

As mídias e formatos variaram, indo de quadro negro e papel e lápis a softwares específicos e, estratégias verbais. Os procedimentos de ensino também variaram, mas podemos observar que alguns estudos utilizaram mídias e procedimentos similares. Um exemplo são os estudos de Pennington: todos envolveram softwares, prompts atencionais e prompts simultâneos, (considerados manipulação de antecedentes) e elogios e feedback auditivo do software que realizava a leitura da história construída pelo participante (considerados manipulação de consequências). A análise dos artigos parece revelar que apesar da variabilidade à primeira vista, quando os artigos de determinado autor são examinados em detalhe, percebe-se que tal autor vem, aos poucos, refinando a utilização de determinadas mídias e procedimentos.

É importante ressaltar que os todos os estudos utilizaram pacotes de intervenção como procedimento, ou seja, muitos elementos estavam envolvidos no ensino de cada habilidade-alvo. Como discutido por Ward-Horner e Sturmey (2010), pesquisas futuras deveriam avaliar o papel de cada componente destas intervenções. Deveriam avaliar também como interações específicas entre estes componentes podem afetar a aprendizagem das habilidades-alvo.

Uma outra discussão, que pode ser trazida à tona a partir da análise dos formatos e mídias, é a utilização de tecnologia assistiva para o ensino da escrita. Três dos seis estudos selecionados utilizaram computadores para o ensino da escrita. Tal uso pode ser visto como uma forma de tecnologia assistiva. É necessário que outros aparelhos como tablets e celulares sejam testados como recurso para ensino de escrita para pessoas com TEA, visto que tal transtorno costuma vir associado a déficits motores e tecnologias 
assistivas poderiam auxiliar na resolução deste tipo de problema (QUEDAS-CATELLI; D'ANTINO; BLASCOVI-ASSIS, 2016). O uso de tecnologia assistiva faz parte do processo de inclusão e deve ser estudado de forma que os melhores resultados possíveis possam ser alcançados por cada indivíduo, neutralizando barreiras causadas pelo atraso motor (SANTOS et al., 2017).

Os ambientes de aprendizagem foram variados, não havendo dados que indiquem que determinado ambiente seja facilitador da aprendizagem destas habilidades.

Em relação ao tempo necessário para aprendizagem dos comportamentos-alvo, a grande variação nos resultados reflete a variedade de comportamentos alvo e de procedimentos de ensino utilizados. Para podermos comparar a efetividade dos procedimentos, os comportamentos-alvo deveriam permanecer os mesmos e apenas mudanças sistemáticas nos procedimentos de ensino deveriam ser 0 alvo de investigações. Sem a homogeneização de variáveis dependentes e a manipulação sistemática das variáveis independentes não é possível a comparação da efetividade dos estudos.

É importante discutir que para que intervenções efetivas ${ }^{7}$ possam ser delineadas, além de estudos empíricos sobre tais intervenções, é necessária a elaboração e validação de medidas das diferentes habilidades de escrita. Apesar de alguns estudos nacionais descreverem instrumentos para a avaliação da escrita de crianças (LEON et al., 2016), não encontramos pesquisas específicas para as pessoas com TEA. Dadas as peculiaridades desta população, avaliações específicas, que levassem em consideração os déficits que costumam ocorrer enquanto comorbidades do TEA, seriam importantes.

Este estudo possui inúmeras limitações, sendo a principal o fato que optamos por analisar apenas artigos que estivessem disponíveis online e de forma gratuita. Tal decisão foi tomada tendo em vista o custo do acesso a informações dentro de periódicos pagos ( $p$. ex., para periódicos com acesso fechado, um artigo pode chegar a custar $U \$ 50,00$ ) e resultou na exclusão de artigos que poderiam adicionar às habilidades-alvo e aos procedimentos aqui descritos. Outra limitação importante foi a ausência de análise da efetividade de cada um dos procedimentos descritos. Muitas revisões sistemáticas têm em vista a análise da efetividade de cada intervenção encontrada, sejam os delineamentos de grupo ou de sujeito único. Revisões futuras poderiam incluir medidas de efetividade para os estudos analisados. Uma outra limitação foi o uso de perguntas específicas para o direcionamento das buscas e análises; tal especificidade limita a 
abordagem de questões mais gerais em relação à escrita. Outras limitações de revisões sistemáticas como a heterogeneidade dos estudos encontrados, possíveis vieses de cada estudo individual e necessidade de atualização contínua também se aplicam a este manuscrito (MENDES-DA-SILVA, 2019).

Apesar de tais limitações, revisões sistemáticas periódicas, que incluam bases de dados nacionais e internacionais e possivelmente manuais de práticas baseadas em evidência para o TEA, são recomendadas como forma de sistematização da literatura para aqueles que necessitam de dados atualizados e organizados. Esta pesquisa não incluiu manuais porque nenhum dos procedimentos para ensino de escrita para pessoas com TEA constava como possuindo evidência suficiente. Por exemplo, no manual de Wong et al. (2014): o Handwriting Without Tears $\AA$, o desenvolvimento de estratégias de auto regulação em intervenções escritas e a técnica de combinação de sentenças (não presente nos artigos aprovados nesta revisão), foram todos considerados como sem evidência suficiente.

Para finalizar, seria importante que futuros estudos empíricos dessem continuidade à investigação das relações entre variáveis dependentes e independentes descritas nos estudos revisados. Além disso, a investigação de outras relações, que não foram alvos das intervenções encontradas, como, por exemplo, o estabelecimento de pré-requisitos e/ou habilidades componentes (JOHNSON; STREET, 2013) ou o papel da tecnologia assistiva no ensino de tais habilidades, seria importante para construir um corpo mais robusto de evidência para o ensino de diferentes habilidades de escrita para pessoas com TEA, especialmente aquelas em estágio inicial de alfabetização.

\section{Referências}

ASARO, K.; SADDLER, B. Effects of planning instruction on a young writer with Asperger syndrome. Intervention in School and Clinic, Washington, D.C, v. 44, n. 5, p. 268-275, 2009 .

ASARO-SADDLER, K.; SADDLER, B. Planning instruction and self-regulation training: Effects on writers with autism spectrum disorders. Exceptional Children, Virgínia, v. 77, n.1, p. 107-124, 2010.

BISHOP, A. E. et al. Effects of a Graphic Organizer Training Package on the Persuasive Writing of Middle School Students with Autism. Education and Training in Autism and Developmental Disabilities, Nova lorque (New York), v. 50, n. 3, p. 290-302, 2015.

BRASIL. Ministério da Educação. PNA Política Nacional de Alfabetização. Secretaria de 
Alfabetização. - Brasília: MEC, SEALF, 2019. 54 p. Disponível em:

http://portal.mec.gov.br/images/banners/caderno_pna_final.pdf. Acesso em: 21 jan. 2020.

CARLSON, B., et al. Teaching preschool children with autism and developmental delays to write. Electronic Journal of Research in Educational Psychology, Almeria, Espanha, v. 7, n.1, p. 225-238, 2009.

\section{COLL, C.; MARCHESI, A.; PALACIOS, J. (Orgs.). Desenvolvimento psicológico e} Educação: psicologia evolutiva. 2. ed. Porto Alegre: Artmed, 2004.

DUEÑAS, A.; BAK, M.Y.S.; PLAVNICK, J. Práticas baseadas em evidência e análise do comportamento aplicada. In: SELLA, A. C.; RIBEIRO, D.M. Análise do Comportamento Aplicada ao Transtorno do Espectro Autista. Curitiba: Appris, 2018. P. 83-102.

GERSTEN, R., et al. Quality indicators for group experimental and quasi-experimental research in special education. Exceptional children, Virgínia, v. 71, n. 2, p. 149-164, 2005.

GRAHAM, S.; HARRIS, K. R. A components analysis of cognitive strategy training: Effects on learning disabled students' compositions and self-efficacy. Journal of Educational Psychology, Washington DC, v. 81, n. 3, p. 353-361, 1989.

GRAHAM, S., \& HARRIS, K. R. (2005). Writing better: Effective strategies for teaching students with learning difficulties. Baltimore: Paul $\mathrm{H}$. Brookes Publishing Co.

GRAHAM, S.; HARRIS, K. R.; LARSEN, L. Prevention and Intervention of Writing Difficulties for Students with Learning Disabilities. Learning Disabilities Research and Practice, Nova Jersei (New Jersey), v. 16, n. 2, p. 74-84, 2001.

GUILHARDI, C. et al. A formação do profissional que trabalha com ABA (Análise do Comportamento Aplicada) e Transtorno do Espectro Autista. Documentos de orientação da comissão de desenvolvimento atípico, São Paulo, 2019. Disponível em http://abpmc.org.br/arquivos/publicacoes/154464258094a735f598.pdf Acesso em: 3 jun. 2020.

HORNER, R. H., et al. The use of single subject research to identify evidence-based practice in special education. Exceptional Children, Virgínia, v. 71, n. 2, p.165-179, 2005.

INEP. Sistema de Avaliação da educação Básica (SAEB): evidências da edição 2017. 68 slides. Brasília: INEP/Ministério da Educação, ago 2018. Disponível em: http://portal.mec.gov.br/index.php?option=com_docman\&view=download\&alias=94161 saeb-2017-versao-ministro-revfinal\&category_slug=agosto-2018-pdf\&ltemid=30192. Acesso em: 16 de jan. 2019.

JENSEN, M.; SMOLEN, C.; GIRIRAJAN, S. Gene discoveries in autism are biased towards comorbidity with intellectual disability. Journal of Medical Genetics, Londres, online, p.1-6, 2020. 
JOHNSON, K.; STREET, E. M. Response to intervention and precision teaching: creating synergy in the classroom. New York, NY: The Guilford Press, 2013.

JOSEPH, L. M.; KONRAD, M. Teaching students with intellectual or developmental disabilities to write: A review of the literature. Research in Developmental Disabilities, Londres (London), v. 30, n. 1, p. 1-19, 2009.

KRATOCHWILL, T. R.; STOIBER, K. C. Evidence-based interventions in school psychology: Conceptual foundations of the procedural and coding manual of division 16 and the society for the study of school psychology task force. School Psychology Quarterly, Washington, D.C, v. 17, n. 4, p. 341-389, 2002.

LEON, C. B. R. et al. Como avaliar a escrita?: revisão de instrumentos a partir das pesquisas nacionais. Revista psicopedagogia, São Paulo, v. 33, n. 102, p. 331-345, 2016.

MENDES-DA-SILVA, W. Contribuições e Limitações de Revisões Narrativas e Revisões Sistemáticas na Área de Negócios. Revista de Administração Contemporânea, Curitiba, v. 23, n. 2, p. 1-11, mar. 2019.

PENNINGTON, R. C. Write on! Using assistive technology and systematic instruction to teach sentence writing to students with moderate to severe disability. Journal of Special Education Technology, Califórnia, v. 31, n. 1, p. 50-57, 2016.

PENNINGTON, R. C. et al. Using simultaneous prompting and computer-assisted instruction to teach story writing to students with autism. Assistive Technology Outcomes and Benefits, Illinois, v. 7, n. 1, p. 24-38, 2011.

PENNINGTON, R. C. et al. Using simultaneous prompting and computer-assisted instruction to teach narrative writing skills to students with autism. Education and Training in Autism and Developmental Disabilities, Nova lorque, v. 49, n.3, p. 396-414, 2014.

PENNINGTON, R. C.; DELANO, M.E. Writing instruction for students with autism spectrum disorders: a review of literature. Focus on Autism and Other Developmental Disabilities, Califórnia, v. 27, n. 3, p. 158-167, 2012.

PENNINGTON, R. C. et al. Using simultaneous prompting to teach computer-based story writing to a student with autism. Education and Treatment of Children, Virgínia, v.35, n. 3, p. 389-406, 2012.

QUEDAS-CATELLI, C. L. R.; D'ANTINO, M. E. F.; BLASCOVI-ASSIS, S. M. Aspectos motores em indivíduos com transtorno do espectro autista: revisão da literatura.

Cadernos de Pós-Graduação em Distúrbios do Desenvolvimento, São Paulo, v.16, n.1, p. 56-65, 2016.

SADDLER, B.; ELLIS-ROBINSON, T.; ASARO-SADDLER, K. Using sentence combining instruction to enhance the writing skills of children with learning disabilities. Learning

Disabilities - A Contemporary Journal, Renânia do Norte-Vestfália, Alemanha, v. 16, n. 
http://dx.doi.org/10.5902/1984686X43482

2, p. 191-202, 2018.

SAMPAIO, C.M.T.; OLIVEIRA, G.F. O desafio da leitura e da escrita em crianças com perturbação do espectro do autismo. Id on line: Revista Muldisciplinar e de Psicologia. Jaboatão dos Guararapes, PE, v. 11, n. 36, p. 343-362, jul 2017.

SANTANGELO, T.; OLINGHOUSE, N. G. Effective writing instruction for students who have writing difficulties. Focus on Exceptional Children, Kansas, v. 42, n. 4, p. 1-20, 2009.

SANTOS, J. J. S.; SELLA, A. C.; RIBEIRO, D. M. Delineamentos intrassujeitos na avaliação de práticas psicoeducacionais baseadas em evidência. Psicologia em Estudo, Maringá, v. 24, p. 1-17, 2019.

SANTOS, R. F. et al. Tecnologia assistiva e suas relações com a qualidade de vida de pessoas com deficiência. Revista de Terapia Ocupacional da Universidade de São Paulo, São Paulo, v.28, n.1, p. 54-62, 2017.

SELLA, A. C.; CHIODELLI, T.; MENDES, C. A. Uma revisão sistemática de comportamentos pré-linguísticos e primeiros comportamentos linguísticos em crianças cegas congênitas. Revista Brasileira de Educação Especial, Marília, v. 19, n. 3, p. 465480, set. 2013.

STEINBRENNER, J.R.; HUME, K.; ODOM, S.L. et al. Evidence- based practices for children, youth, and young adults with autism. 2020.

THE WRITING CENTER, UNIVERSITY OF NORTH CAROLINA AT CHAPEL HILL. Applied Behavioral Analysis: How to Write a Literature Review. 2018. Disponível em: http://libguides.regiscollege.edu/c.php?g=920226\&p=6631181. Acesso em 20 jan. 2018.

WARD-HORNER, J.; STURMEY, P. Component analyses using single-subject experimental designs: A review. Journal of applied behavior analysis, Lawrence, v. 43, n.4, p. 685-704, 2010.

WONG, C. et al. Evidence-based practices for children, youth, and young adults with Autism Spectrum Disorder. Chapel Hill: The University of North Carolina, Frank Porter Graham Child Development Institute, Autism Evidence-Based Practice Review Group, 2014.

\section{Notas}

${ }^{1}$ A escrita é uma das formas mais importantes de comunicação humana e uma das mais difíceis de se fazer bem. A escrita fornece uma ferramenta maravilhosamente flexível para a aquisição, a lembrança e a disseminação de conhecimento para os outros enquanto também oferece um meio artístico para a autoexpressão criativa. (SADDLER; ELLIS-ROBINSON; ASARO-SADDLER, 2018, p. 191, tradução nossa).

${ }^{2}$ A definição de práticas baseadas em evidência (PBEs) e de efetividade variam muito a depender dos parâmetros adotados pelos autores ou bases de dados (p. ex., What Works ClearingHouse versus Cochrane versus National Autism Center). Para uma descrição acerca dos critérios utilizados pelos autores, recomenda-se que os leitores visitem o texto. Ao longo do presente manuscrito, PBEs são entendidas como a integração (a) de práticas de intervenção que possuem demonstração de efeitos positivos sobre o 
desenvolvimento de pessoas com TEA, com (b) o contexto individual de cada uma destas pessoas, (c) a expertise clínica profissional e (d) a coleta de dados local que informe as decisões diárias acerca do curso da intervenção (DUEÑAS; BAK; PLAVNICK, 2018). Importante dizer que a Comissão de Desenvolvimento Atípico da Associação Brasileira de Medicina e Psicoterapia Comportamental (ABPMC) utiliza parâmetros advindos dos Estados Unidos e Canadá como base para avaliação de PBEs (GUILHARDI et al., 2019).

${ }^{3}$ Ambos os critérios de (1) ser empírico, ou seja, aquele estudo em que há observação direta do fenômeno alvo e o de (2) ser um estudo de intervenção, ou seja, estudos em que se manipula a variável independente para gerar mudanças na variável dependente tinham de ser cumpridos no item (f).

${ }^{4}$ Prompts, elogios enquanto reforçadores condicionados e feedback fazem parte das intervenções com suporte empírico conforme relatório mais recente do National Clearinghouse on Autism Evidence \& Practice (NACEP, 2020).

${ }^{5}$ Dada a riqueza de detalhes que o uso fidedigno de cada uma destas mídias requer, recomendamos a leitura dos artigos para aqueles que decidirem utilizar as mesmas.

${ }^{6}$ Instrução Assistida por Computador (CAI) se refere a qualquer programa que tem por objetivo o ensino de qualquer habilidade, conceito, princípio ou estratégia, ou seja, qualquer conteúdo instrucional, quando tal programa é apresentado por um computador.

${ }^{7}$ A discussão sobre o que faz de uma prática efetiva é bastante complexa e varia dentro das diversas perspectivas teóricas acerca da aprendizagem. No contexto deste estudo, se a efetividade das pesquisas fosse analisada, seriam adotados como critérios de avaliação para delineamentos de sujeito único os iniciados por Horner et al. (2005) e para delineamentos em grupo, os iniciados por Gersten et al. (2005). É importante ressaltar que estes critérios já foram e são constantemente refinados por diversas organizações que constrõem sínteses de pesquisas, como o WWC, NAC, NPDC e NACEP. Isto significa que se a efetividade dos estudos tivesse sido analisada neste manuscrito, intervenções efetivas seriam aquelas que demonstrassem mudanças no comportamento-alvo de acordo com os critérios descritos para uma intervenção ser considerada com suporte empírico de acordo com tais organizações.

\section{Correspondência}

Ana Carolina Sella - Universidade Federal de Alagoas, Centro de Educação (CEDU), Tabuleiro do Martins, Maceió, Alagoas - Brasil.

CEP: $57072-900$

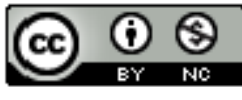

This work is licensed under a Creative Commons Attribution-NonCommercial 4.0 International (CC BY-NC 4.0) 